\title{
Carbon Storage and Sequestration of National Key Ecological Restora- tion Programs in China: An Introduction to Special Issue
}

\author{
LIU Guohua, WU Xing \\ (State Key Laboratory of Urban and Regional Ecology, Research Center for Eco-Environmental Sciences, Chinese Academy of Sci- \\ ences, Beijing 100085, China)
}

Although a crucial objective of ecosystem management should be the avoidance of degradation at the beginning, an unfortunate truth is that ecosystems have been substantially exploited, degraded and destroyed in the last century as a result of the global increase in economic and societal prosperity (Suding, 2011). More than 60\% of ecosystems have been converted for human use or degraded through unsustainable harvest, pollution, fragmentation or exotic species invasions (Millennium Ecosystem Assessment, 2005). As these influences increasingly compromise environmental sustainability, human health, biodiversity and food security, the restoration of degraded ecosystems is becoming a primary focus of natural resource management for both policy makers and scientists (Harris et al., 2006; Wortley et al., 2013).

Ecological restoration, which aims to restore the over-exploited or degraded ecosystems, has been a crucial approach to mitigate human pressures on natural ecosystems and to enhance ecosystem services (Holl et al., 2003; Feng et al., 2013). Although a large number of restoration practices have been widely incorporated into natural resource strategies from the local to global scales, there are still uncertainties as to how effective restoration programs actually are (Suding, 2011; Wortley et al., 2013). Moreover, few countries face ecosystem degradation problems as severe as those in China (Ma et al., 2013). During the past several decades, a series of environmental problems gradually arose due to irrational utilization of land and excessive consumption of natural resources. To alleviate widespread soil erosion and desertification and protect natural resources, the Chinese government has implemented unprecedented projects and policies to restore vast areas of degraded land (Cao et al., 2011a). These projects, especially several national key ecological restoration programs, have affected huge areas of China, accompanied by vast investments (Ma et al., 2013).

Due to the severity of the environmental problems that China encountered and the large sums of investment being spent, it is essential to evaluate the efficiency of these ecological restoration programs. Therefore, appropriate monitoring is necessary for investigating the comprehensive effects of these programs that have not been fully understood. Although there is a growing number of studies demonstrating that ecological restoration could increase vegetation coverage, reduce soil erosion and enhance the biodiversity and ecosystem services (Rey Benayas et al., 2009; Cao et al., 2011a; Yang et al., 2014), ecosystem function, such as carbon sequestration, was rarely considered in restoration projects, especially for the national key ecological restoration programs in China (Feng et al., 2013; Wei et al., 2013). The large scale of land use change undertaken for these ecological restoration programs may indeed enhance carbon sequestration capacity in the terrestrial ecosystems of China and contribute significantly to the mitigation of climate change (Piao et al., 2009; Cao et

Received date: 2014-03-28; accepted date: 2014-05-04

Foundation item: Under the auspices of Strategic Priority Research Program of Chinese Academy of Sciences (No. XDA05060100),

National Natural Science Foundation of China (No. 41105117)

Corresponding author: LIU Guohua. E-mail: ghliu@rcees.ac.cn

(C) Science Press, Northeast Institute of Geography and Agroecology, CAS and Springer-Verlag Berlin Heidelberg 2014 
al., 2011b). However, so far there has been little comprehensive assessment of the changes in ecosystem carbon storage for the entire national ecological restoration programs despite many observations made at the local scale (Feng et al., 2013; Wei et al., 2013).

In order to quantify the carbon sequestration rates and potentials of these national ecological restoration programs with relatively low uncertainties, the Chinese Academy of Sciences has launched a strategic priority research program-'Climate Change: Carbon Budget and Relevant Issues', in 2011. There are 15 sub-projects in it with different scientific purposes. The main objectives of one sub-project were to assess the carbon sequestration rates and spatio-temporal differences of six national key ecological restoration programs, and to improve these programs for better contributions to the mitigation of and adaptation to climate change.

This special issue of 'Carbon Storage and Sequestration of National Key Ecological Restoration Programs in China' provides a series of current research concerning the effects of China's national ecological restoration programs on ecosystem or soil carbon storage and sequestration potential. The main theme of this special issue is to address how ecological restoration programs affect plant growth, carbon sequestration, soil carbon process and their intrinsic correlations and mechanisms. The contributions cover a range of different ecosystems (e.g., forest, shrubland and grassland) with different management practices (e.g., afforestation on degraded lands, nature restoration and succession, grazing exclusion), and extend across a wide range of ecological zones (e.g., the Loess Plateau, the Changbai Mountains, the Qinghai-Tibet Plateau and the Hulun Buir Grassland) by using different research approaches (e.g., long-term field investigation, national forest inventories).

Two papers deal specifically with carbon storage and sequestration of the Natural Forest Protection (NFP) program. Wei et al. (2014) used forest inventory databases and field experiment databases in the forest region of the northeastern China to calculate forest ecosystem carbon storages (tree, understory, forest floor and soil) after the implementation of the NEP program. This case study clearly demonstrated that soil was the largest carbon storage component, contributing $69.5 \%-77.8 \%$ of ecosystem carbon storage; while tree and forest floor carbon pools accounted for $16.3 \%-23.0 \%$ and $5.0 \%-$
$6.5 \%$ of total carbon storage, respectively. Zhou et al. (2014) calculated the biomass carbon storage in the first-stage (1998-2010) of the NEP program by using China's seventh forest inventory dataset, stand volume of different types and age-classes of forest plantations. Moreover, they estimated the carbon sequestration potential for the second-stage (2011-2020) of the NEP program. The results showed that biomass carbon storage of forest plantations established in the first-stage was $33.67 \mathrm{Tg} \mathrm{C}$, and the carbon storage was projected to 96.03 Tg C at the end of the second-stage of the NEP program.

The Grain for Green (GFG) program, one of the world's most ambitious conservation set-aside programs, has been the largest ecological restoration project since the 1990s in China (Feng et al., 2013). Li and Liu (2014) investigated an age-sequence of black locust forest $(5 \mathrm{yr}, 9 \mathrm{yr}, 20 \mathrm{yr}, 30 \mathrm{yr}, 38 \mathrm{yr}$, and $56 \mathrm{yr}$ since planting) on the Loess Plateau to evaluate carbon accumulation and allocation in plants (trees, shrubs, herbs, and leaf litter) and soil. Their study demonstrated that black locust forest accumulated carbon constantly, from $31.42 \mathrm{Mg} \mathrm{C} /$ ha at $5 \mathrm{yr}$ to $79.44 \mathrm{Mg} \mathrm{C} / \mathrm{ha}$ at $38 \mathrm{yr}$, and that succession plays a key role in carbon accumulation and re-allocation in black locust forests and also in regional carbon dynamics in vegetation. Tang et al. (2014) examined the characteristics of Medicago sativa L. grassland biomass carbon and soil organic carbon density in a loess hilly region with different growing years and management patterns by using spatial-temporal substitution approach. The results indicated that different management patterns imposed great different effects on the accumulation of biomass carbon on artificial grasslands, whereas the ecosystem carbon density of the grassland showed a slight increase from the clipping to abandonment of grassland in general. Hu et al. (2014) compared the soil carbon stock and flux of two main vegetation types (forest and grassland) after cropland abandoned for 25 years. Their findings suggested that black locust plantation forest on hill slopes might be better than grassland in terms of carbon sequestration since black locust had a higher soil carbon stock and lower carbon flux.

By performing a series of paired-field experiments, Zeng et al. (2014) estimated the effects of revegetation types and environmental conditions on soil organic carbon (SOC) stock and vertical distribution after replace- 
ment of cropland with poplar and korshinsk peashrub in three climatic regions of the Beijing-Tianjin Sandstorm Source Control (BTSSC) program area. Their results indicated that cropland afforestation not only affects SOC stock in the topsoil, but also has some effects on subsoil carbon. However, the effect of cropland afforestation on SOC accumulation varied with climate regions and revegetation types. In a similar research, Shen et al. (2014) accessed the carbon storage capacity of different plantation types under the BTSSC program in Hebei Province. The findings suggested that tree species should be incorporated into accurately develop regional carbon budget of afforestation program, and implied that substantial differences in ecosystem carbon stocks among plantation types can facilitate decision making on carbon management.

The Three-North Shelterbelt Forest (TSF) program, accounting for $42.4 \%$ of China's land area, is one of six key forestry programs in China. Liu Wenhui et al. (2014) investigated the distribution area and the carbon sequestration capacity of shrubs in the TSF program region based on the remote-sensing images taken from 1978 to 2008 . This study provided a baseline reference for future studies on the carbon sequestration of shrubs on a large-scale, because of the paucity of studies and data available on the large-scale carbon sequestration levels of shrub species.

Three papers are dedicated to studies concerning the effects of different management practices on vegetation traits, soil properties and soil carbon storage within the Returning Grazing Lands to Grasslands (RGLG) program. Liu Miao et al. (2014) tested the hypothesis that different management practices (e.g., grazing, mowing and fencing) triggered significant variation of biomass partitioning and carbon reallocation in Hulun Buir Grassland. Their results suggested that the RGLG program played a positive role in sustainable grasslands utilization of Hulun Buir Region and had a strong positive influence on the entire temperate grasslands. In the similar study area, Wu et al. (2014) evaluated the effects of grazing exclusion on soil carbon and nitrogen storage due to the RGLG program in semi-arid grassland of Inner Mongolia by establishing paired long-term free grazing plots and adjacent grazing exclusion plots. Their findings indicated that removal of grazing pressure within the RGLG program was an effective restoration approach to control grassland degradation in this region.
Xiong et al. (2014) investigated the effects of grazing exclusion on plant productivity, species diversity and soil organic carbon and soil total nitrogen storage along a transect spanning from east to west of alpine meadows in the northern Tibet. Their results also proved that grazing exclusion is an effective measure to increase forage production and enhance soil carbon sequestration in Qinghai-Tibet Plateau, and suggested that grazing exclusion should be combined with other measures to reconcile grassland restoration and biodiversity conservation.

In general, there are increasing studies concerning the effects of different ecological restoration practices on carbon storage and sequestration in China. Although this special issue provided 11 case studies from local to regional scales, the potential links between China's ongoing national ecological restoration programs and the resulting changes of natural factors such as vegetation communities, soil carbon process and climate change are still poorly understood. Therefore, more long-term studies have to be carried out for different vegetation types and restoration practices under different climatic conditions, and to enhance the comprehensive multidisciplinary researches for better ecological restoration strategies. We hope that this special issue will generate more intensive research on the use of appropriate ecological restoration practices to reduce ecosystem degradation and to mitigate climate change impact, and that it will promote effective international communication, collaboration and cooperation for a better understanding of the national ecological restoration programs in China.

\section{Acknowledgements}

We are grateful to Chinese Geographical Science for the opportunity to publish these important case studies and to the editors for their great contribution to managing this special issue.

\section{References}

Cao S, Chen L, Shankman D et al., 2011a. Excessive reliance on afforestation in China's arid and semi-arid regions: Lessons in ecological restoration. Earth-Science Reviews, 104(4): 240245. doi: 10.1016/j.earscirev.2010.11.002

Cao S, Sun G, Zhang Z et al., 2011b. Greening China naturally. AMBIO, 40(7): 828-831. doi: 10.1007/s13280-011-0150-8

Feng X M, Fu B J, Lu N et al., 2013. How ecological restoration 
alters ecosystem services: An analysis of carbon sequestration in China's Loess Plateau. Scientific Reports, 3: 2846. doi: 10.1038/srep02846

Harris J A, Hobbs R J, Higgs E et al., 2006. Ecological restoration and global climate change. Restoration Ecology, 14(2): 170-176. doi: 10.1111/j.1526-100X.2006.00136.x

Holl K D, Crone E E, Schultz C B, 2003. Landscape restoration: Moving from generalities to methodologies. BioScience, 53(5): 491-502. doi: 10.1641/0006-3568(2003)053[0491: LRMFGT]2.0.CO;2

Hu Chanjuan, Liu Guohua, Fu Bojie et al., 2014. Soil carbon stock and flux in plantation forest and grassland ecosystems in Loess Plateau, China. Chinese Geographical Science, 24(4): 423-435. doi: 10.1007/s11769-014-0700-7

Li Taijun, Liu Guobin, 2014. Age-related changes in carbon accumulation and allocation in plants and soil of black locust forest on Loess Plateau in Ansai County, Shaanxi Province of China. Chinese Geographical Science, 24(4): 414-422. doi: 10.1007/s11769-014-0704-3

Liu Miao, Liu Guohua, Wu Xing et al., 2014. Vegetation traits and soil properties in response to utilization patterns of grassland in Hulun Buir City, Inner Mongolia, China. Chinese Geographical Science, 24(4): 471-478. doi: 10.1007/s11769014-0706-1

Liu Wenhui, Zhu Jiaojun, Jia Quanquan et al., 2014. Carbon sequestration effects of shrublands in Three-North Shelterbelt Forest Region, China. Chinese Geographical Science, 24(4): 444-453. doi: 10.1007/s11769-014-0698-x

Ma H, Lv Y, Li H, 2013. Complexity of ecological restoration in China. Ecological Engineering, 52: 75-78. doi: 10.1016/j. ecoleng.2012.12.093

Millennium Ecosystem Assessment, 2005. Ecosystems and Human Well-being: Synthesis. Washington, D.C.: Island Press.

Piao S, Fang J, Ciais P et al., 2009. The carbon balance of terrestrial ecosystems in China. Nature, 458(7241): 1009-1013. doi: 10.1038 /nature 07944

Rey Benayas J M, Newton A C, Diaz A et al., 2009. Enhancement of biodiversity and ecosystem services by ecological restoration: A meta-analysis. Science, 325(5944): 1121-1124. doi: 10.1126/science. 1172460

Shen Huitao, Zhang Wanjun, Yang Xue et al., 2014. Carbon storage capacity of different plantation types under Sandstorm Source Control program in Hebei Province, China. Chinese Geographical Science, 24(4): 454-460. doi: 10.1007/s11769-014-
0699-9

Suding K N, 2011. Toward an era of restoration in ecology: Successes, failures, and opportunities ahead. Annual Review of Ecology, Evolution, and Systematics, 42: 465-487. doi: 10.1146/annurev-ecolsys-102710-145115

Tang Long, Dang Xiaohu, Liu Guobin et al., 2014. Response of artificial grassland carbon stock to management in mountain region of southern Ningxia, China. Chinese Geographical Science, 24(4): 436-443. doi: 10.1007/s11769-014-0705-2

Wei X, Li Q, Liu Y et al., 2013. Restoring ecosystem carbon sequestration through afforestation: A sub-tropic restoration case study. Forest Ecology and Management, 300: 60-67. doi: 10.1016/j.foreco.2012.06.018

Wei Yawei, Yu Dapao, Lewis Bernard Joseph et al., 2014. Forest carbon storage and tree carbon pool dynamics under Natural Forest Protection program in northeastern China. Chinese Geographical Science, 24(4): 397-405. doi: 10.1007/s11769014-0703-4

Wortley L, Hero J, Howes M, 2013. Evaluating ecological restoration success: A review of the literature. Restoration Ecology, 21(5): 537-543. doi: 10.1111/rec.12028

Wu Xing, Li Zongshan, Fu Bojie et al., 2014. Effects of grazing exclusion on soil carbon and nitrogen storage in semi-arid grassland in Inner Mongolia, China. Chinese Geographical Science, 24(4): 479-487. doi: 10.1007/s11769-014-0694-1

Xiong Dingpeng, Shi Peili, Sun Yinliang et al., 2014. Effects of grazing exclusion on plant productivity and soil carbon, nitrogen storage in Alpine Meadows in northern Tibet, China. Chinese Geographical Science, 24(4): 488-498. doi: 10.1007/ s11769-014-0697-y

Yang H, Mu S, Li J, 2014. Effects of ecological restoration projects on land use and land cover change and its influences on territorial NPP in Xinjiang, China. Catena, 115: 85-95. doi: 10.1016/j.catena.2013.11.020

Zeng Xinhua, Zhang Wanjun, Liu Xiuping et al., 2014. Change of soil organic carbon after cropland afforestation in 'BeijingTianjin Sandstorm Source Control' program area in China. Chinese Geographical Science, 24(4): 461-470. doi: 10.1007/s11769-014-0701-6

Zhou Wangming, Lewis Bernard Joseph, Wu Shengnan et al., 2014. Biomass carbon storage and its sequestration potential of afforestation under Natural Forest Protection program in China. Chinese Geographical Science, 24(4): 406-413. doi: 10.1007/s11769-014-0702-5 